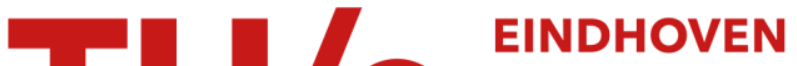

\section{The promise of peer-to-peer trading? The potential impact of blockchain on the actor configuration in the Dutch electricity system}

\section{Citation for published version (APA):}

Buth, M. C., Wieczorek, A. J., \& Verbong, G. P. J. (2019). The promise of peer-to-peer trading? The potential impact of blockchain on the actor configuration in the Dutch electricity system. Energy Research and Social Science, 53, 194-205. https://doi.org/10.1016/j.erss.2019.02.021

\section{Document license:}

TAVERNE

DOI:

10.1016/j.erss.2019.02.021

Document status and date:

Published: 01/07/2019

\section{Document Version:}

Publisher's PDF, also known as Version of Record (includes final page, issue and volume numbers)

\section{Please check the document version of this publication:}

- A submitted manuscript is the version of the article upon submission and before peer-review. There can be important differences between the submitted version and the official published version of record. People interested in the research are advised to contact the author for the final version of the publication, or visit the DOI to the publisher's website.

- The final author version and the galley proof are versions of the publication after peer review.

- The final published version features the final layout of the paper including the volume, issue and page numbers.

Link to publication

\footnotetext{
General rights

- You may freely distribute the URL identifying the publication in the public portal. follow below link for the End User Agreement:

www.tue.nl/taverne

\section{Take down policy}

If you believe that this document breaches copyright please contact us at:

openaccess@tue.nl

providing details and we will investigate your claim.
}

Copyright and moral rights for the publications made accessible in the public portal are retained by the authors and/or other copyright owners and it is a condition of accessing publications that users recognise and abide by the legal requirements associated with these rights.

- Users may download and print one copy of any publication from the public portal for the purpose of private study or research.

- You may not further distribute the material or use it for any profit-making activity or commercial gain

If the publication is distributed under the terms of Article $25 \mathrm{fa}$ of the Dutch Copyright Act, indicated by the "Taverne" license above, please 
Original research article

\title{
The promise of peer-to-peer trading? The potential impact of blockchain on the actor configuration in the Dutch electricity system
}

\author{
M.C. (Annemarie) Buth*, A.J. (Anna) Wieczorek, G.P.J. (Geert) Verbong \\ School of Innovation Sciences, Eindhoven University of Technology, the Netherlands
}

\section{A R T I C L E I N F O}

\section{Keywords:}

Energy

Transition

Blockchain

Actor configuration

Social network analysis

Decentralization

Electricity

\begin{abstract}
A B S T R A C T
This paper considers the potential of blockchain technology to empower distributed and decentralized local electricity markets. Although blockchain has gained considerable attention in the last few years as a facilitator for new electricity markets, no attention has yet been given to its potential influence on the configuration of the actors in the electricity system and its ability to transform the existing system. Based on a social network analysis, this paper investigates how blockchain can influence the actor configuration of the electricity system in the Netherlands. After describing the Dutch system, we compare the existing with the potential future system' actor configuration and the corresponding expected shifts in functions and network position of the actors. We conclude that although many functions are likely to remain and new central authorities may be formed, the impact of blockchain does not seem to be as disruptive and decentralizing as may be expected. This study provides first contributions to the ongoing discussion about the potential of blockchain to disrupt and reshape the electricity system.
\end{abstract}

\section{Introduction}

To date, electricity has been generated mostly by centralized power plants from reliable but unsustainable fossil fuel energy sources [1]. Due to growing distress about climate change, the depletion of fossil fuels and concerns about local economies, a transition towards sustainable energy began to unfold [2]. The transition embodies a shift towards more decentralized and renewable energy-based generation where users are encouraged to become prosumers and generate own renewable electricity [3]. The significant growth of the intermittent renewable energy based on distributed generation, challenges the current electricity system [4]. The unpredictable fluctuations may lead to power outages, service perturbations or overload in electricity components, thereby threatening the stability of the energy supply. These problems are expected to proliferate as current trends envisage further increase in use of electric vehicles, heat pumps growing number of installed solar panels at residences and an extended consumer engagement [5-7]. Accordingly, an urgent need is growing for novel grid management architectures that can cope with this decentralized energy production and use [3,8-10].

One of the potential promising architectures is the Local Energy Markets (LEM) approach, denoting markets that enable consumers and prosumers to trade energy within their community, facilitate (near)realtime pricing and assist the process of a local balance of supply and demand [11]. LEM have thereby the potential to empower and actively engage small-scale prosumers in the electricity system. LEM may this way facilitate "decentralized, smart, and interconnected markets" ([12], p. 10). Support to LEM is thus high on the strategic agenda of the European Commission [13]. To operate in a smart way however, LEM require advanced information and communication technology (ICT) $[14,15]$ that not only facilitates the local energy generation, trading, near real-time pricing and balancing, but also provides a secure way to do so. Blockchain is a technology that holds a promise to do all this.

Blockchain is a cryptographically sealed and fully distributed electronic database (a ledger) that is chronologically and continuously updated and replicated over a peer-to-peer network. This distributed ledger can be used as an accounting system for transactions between peers or for registering all kinds of assets on a global scale between all participants that are connected to the ledger. Being cryptographically sealed, the transactions cannot be altered retrospectively, and the parties involved no longer need to trust a third party to advance the transaction. Consequently, blockchain is widely regarded to enable the decentralization and disintermediation of any transaction between parties on a global scale [16-18]. Since blockchain is a distributed ledger technology, it is said to have the potential to empower decentralized markets and it therefore offers an opportunity to facilitate LEM [9,11,19,20].

Both academic literature $[18,21]$ as well as non-academic sources [22-25] expect blockchain to fundamentally change industries: the current blockchain stage is often compared to the early days of the internet in the

\footnotetext{
* Corresponding author.

E-mail address: annemarie_buth@hotmail.com (M.C. Buth).
} 
$90 \mathrm{~s}$. Along with this potential, it embodies the possibility to radically alter the electricity system by means of replacing various mostly intermediary actors, such as energy utilities. This leads to concerns and growing fear among industrial actors about the potential redundancy of their existence [26-29]. Although blockchain has gained considerable attention in the last few years as a facilitator for the conceptualization and implementation of new energy markets such as LEM $[3,9,11,19,20]$, no attention has yet been given to its specific influence on the configuration of the actors in the electricity system and its ability to transform the existing system.

In this article we aim to fill in this gap. In particular, we build on the insights from the rapidly evolving transition studies regarding the conceptualization and the role of networks in the development of new technologies and in the unfolding broader processes of radical change [30-33]. By making use of a Social Network Analysis (SNA) as well as one normative scenario, we explore two possible ways in which blockchain can influence the function(s) of the various system' actors and their position in the social network in the ongoing energy transition. We address the following research question:

How could the introduction of blockchain in the Dutch electricity system influence its actor configuration?

Although the influence of blockchain is not limited to geographical borders, our analysis takes the Dutch socio-technical electricity system as a unit of analysis due to its specific characteristics and recent developments. The remainder of this paper proceeds as follows. In Section 2, we present our analytical framework. In Section 3, we describe the methods. In Section 4, we present the results of the analysis and we discuss the prospected influence of blockchain on the actor configuration in the electricity system based on the empirical Dutch example. We conclude in Section 5.

\section{Analytical framework}

The evolving field of transition studies [34] recognizes the important role of networks in the development of new technologies and in the processes of transition [30-33]. Transitions are large scale fundamental changes in the way human needs are satisfied. The change denotes not only substantial technological innovation but also equally high-level change in societal aspects - hence socio-technical system change. Most incumbent systems providing human needs, such as energy, are unsustainable but highly path-dependent and locked-in [35]. Alternative technologies like blockchain and novel ways of organizing the socio-technical systems such as the distributed energy generation, are developed in protected spaces: niches.

Network formation, next to learning an expectation articulation is a critical process motivating the alternative niche development [36] but the concept of social network analysis has not been very popular in this field. If social network theory, and social network analysis in particular, was mobilized, it was often to highlight the direct positive impact of networking within niches on the successful incubation of novel technologies. Among the first to recognize the value of social network analysis techniques to study transitions were Caniëls and Romijn [37], who identified the link between networking and various processes influencing niche formation. Their work was taken a step further by Lopolito et al. [38], who used social network analysis techniques to define the internal development status of innovation niches. Later, Hermans et al. [39] studied the network characteristics of a niche as it evolves over time. Other authors made use of social network analysis to investigate the role of networks in relation to innovation performance [32,40,41].

In social network theory, social networks are defined as social structures constituted by a set of actors, also known as nodes, and the relationships between these actors, represented by lines or ties. The nodes can refer to any type of actor (individuals, firms, universities, communities, etc.) and the ties can denote any type of social relationship (e.g. information sharing, transfer of financial resources, exchange of goods or services) [42]. The study of social networks is related to an analytical tool called social network analysis (SNA) $[40,43]$. The SNA can be defined as: the disciplined inquiry into the patterning of relations among social actors, as well as the patterning of relationships among actors at different levels of analysis ([44], p. 508). This tool is used to investigate the relationships among actors in a specific network. It can also be used to analyze the structure and patterns of these relationships by making use of various predefined network properties, which contain valuable information about the relationships within the network. The network properties such as network shape, density, strength of the relation and the degree of connections of an actor, help to better understand the structure and patterns in the networks. By showing actors as nodes, SNA further enables a visualization of the network, which helps to better grasp the relevant abstract features in interaction systems such as working mechanisms of the network $[45,46]$.

The existing literature on the effect of networks on innovation performance distinguishes two major research streams: the ego-centric perspective and the socio-centered perspective [47]. The ego-centric (or personal) network perspective focusses on the innovation performance of individuals and analyses the local network structure from a focal actor's perspective only whereas the socio-centered (or complete) network perspective focusses on the innovation performance of organizations and analyses the overall network structure [47]. Another, relevant distinction made in the SNA type of analyses is between two views of network analysis: the structuralist and the connectionist [48]. The structuralist approach focusses on the topology of social relations within networks. Coleman [49] argues that if networks are dense (i.e. they have many actors within the network) and deep (i.e. the relationship is strong), they have a high level of social capital, which safeguards against opportunism and facilitates trust, resulting in more resources and willingness of others within a network to achieve certain goals. Hence, the structuralist approach focusses on the patterns of interconnections rather than the content of the ties. The connectionist view concentrates on the resources (the content) that flow through ties. Networks may stimulate niche development in the sense that if networks are broad, then the knowledge from actors who are weakly linked to the network may provide valuable cognitive knowledge and resources [50]. Hence, the structuralist view focusses on the structure of interconnections within the network, whereas the connectionist view focusses on the type of interconnections within the network and the resources that flow through them [48].

In this paper we use transition insights to conceptualize the current electricity as an incumbent socio-technical system that fulfils the societal function of energy provision. To show its stability, we shortly describe the institutional fabric of the dominant configuration and map the current actors. We also identify a few relevant broad factors that (dis-)stabilize the system, making it open to such technologies as blockchain. Blockchain is here considered as an innovation that has not yet gained sufficient critical mass that would motivate an alternative way of organizing the electricity system. It does however stir unrest among especially large and incumbent actors by carrying the potential of making some of them redundant [26,27]. By means of SNA we therefore unpack the current system' actor configuration and map potential changes brought about by blockchain. Given our interest in understanding and describing how blockchain technology provides an alternative way to organize the electricity system and how it can facilitate the ongoing energy transition, in this paper we adopt the socio-centered perspective using insights from both structuralism and connectionism. This is different to the existing body of literature that connects transition studies to network theory, which predominantly adopts a connectionist approach. The structuralist approach however provides a valuable tool for the systematic analysis and empirical measurement of a network.

\section{Methods}

\subsection{Methodological approach}

To empirically underpin our argument, we investigate the Dutch electricity system. The Netherlands were chosen for their specific institutional context and regulatory framework. The country has a leading position in the development of smart technologies such as blockchain prompted by a strong 


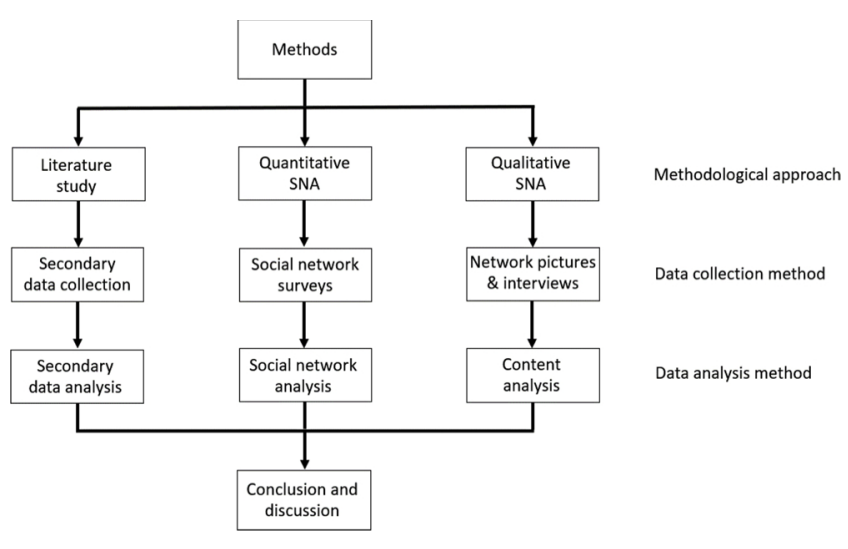

Fig. 1. Process diagram methods.

government support to the formation of a National Blockchain Coalition [51]. The Netherlands also has multiple community driven energy initiatives that apply blockchain technology to facilitate local electricity trading. Examples include De Ceuvel, ran by the grid operator Alliander and software provider Spectral [52]; or Hoog Dalem, ran by the grid operator Stedin and software provider Energy21 [53].

Methodologically, this research synthesizes qualitative and quantitative methods by conducting three types of analyses: a literature study, a quantitative and qualitative SNA (Fig. 1). The literature study was conducted to explain, in transition terms, the dynamics and specifically the actor configuration of the current Dutch electricity system and to formulate one normative scenario. Given the explorative nature of this research, the scenario describes one possible future dynamics and a potential actor configuration of the Dutch electricity system where blockchain enables peer-to-peer trading in LEMs. The scenario thereby captures the trends of growing number of prosumers and decentral energy resources within the grid and the need of managing these developments effectively. The particular peer-to-peer application was selected from many because it is considered the most promising and for its dominance in the existing pilot projects and initiatives [9,54-57]. The year 2030 was chosen to align with the projected time-line of the Dutch climate agreements.

The quantitative SNA was performed to systematically map the actor configuration (nodes) and the inter-organizational relationships (ties) in the existing and the future electricity system. The analysis provided insights in the structural properties of the nodes and the overall network. It contributed thereby to the testing of the socio-centric and structuralist approach. The qualitative SNA was conducted to create an overview and to interpret the meaning of the nodes and ties. Moreover, by means of the qualitative SNA, a possible evolution of the actor configuration was enabled with particular attention to the potential novel functions of the actors in the future electricity system. Such a mapping requires a deeper understanding of the wider context and would not be possible with the purely variable-oriented techniques of the quantitative part. In this way, the qualitative SNA contributed to the testing of the socio-centric and connectionist views.

\subsection{Data collection and analysis}

For the literature study (Fig. 1) that would help to map the electricity system and to build the normative scenario, two separate literature studies were conducted based on two academic databases: Scopus and Web of Science respectively ${ }^{1}$. Data from these studies were analyzed by means of secondary data analysis. Based on the analysis,

\footnotetext{
${ }^{1}$ The keywords that were used included: Dutch electricity market, Dutch electricity supply, Dutch energy transition, Dutch electricity system, blockchain electricity, blockchain electricity applications, blockchain peer to peer, blockchain microgrid, blockchain energy and decentralized energy trading.
}

the most common application of blockchain in the electricity system was identified and formed a base for the normative scenario, namely: local energy trading. Since this research served illustrative purposes and did not aim to be all-encompassing, we limited the analysis to investigating the effect of solely this one use case. To avoid personal bias in the interpretation of the cases, the scenario was verified with six experts $^{2}$ from the electricity sector.

For both types of SNA analysis, eleven research participants were selected via snowball-sampling. The actors represented actor groups (e.g. producer, supplier) rather than organizations (e.g. Eneco, TenneT, Enexis). The research participants were selected based on their involvement in the development of blockchain technology within their organization. They predominantly occupied managerial or CEO positions (e.g. manager of the IT department within a Dutch energy company or the strategic manager within a grid operator). They were therefore not only able to understand the potential of blockchain but also to grasp the broader view of the electricity system.

For the quantitative SNA (Fig. 1), data was gathered through social networks surveys. Participants filled in two social network surveys where they were asked to attribute values to the degree of frequency of interaction with other actors in the network ${ }^{3}$ for the existing and the future electricity system. The values of the future electricity system were based upon the interpretation of the normative scenario of the research participants. Accordingly, the surveys resulted in two networks visualizations: the existing actor configuration and the expected future actor configuration. The input from the surveys was used to identify the predefined network properties needed for the analysis and for the comparison of the two networks with each other (see Section 3.3). The quantitative SNA was carried out by making use of social network software called NodeXL. The surveys were used as input and they enabled the visualization of two networks and the computation of various predefined network properties that were needed to analyze the network.

For the qualitative SNA (Fig. 1), data was gathered and analyzed by means of network drawing exercises, which resulted in so-called network pictures. Prior to filling in the second survey, the participants were handed a sheet of paper depicting merely the system actors without ties connecting them. Subsequently, the participants drew lines (i.e. ties) that represented the relationships between the actors, for which they used different colors to indicate changes in interactions compared to the existing system (i.e. relationships which they expected to grow stronger were colored green, whereas weaker was colored red and equal was colored black). In addition, the participants were asked open questions concerning the reasons of changed interactions and potential new actor groups, if $\mathrm{any}^{4}$, and indicated the potential new functions of the actors. The qualitative SNA had the purpose of enriching and corroborating stories and meanings of the interviewees visa-vis the quantitative SNA results.

\subsection{Network properties}

\subsubsection{Overall-level metrics (quantitative SNA)}

By conducting both types of SNA, various network properties were

\footnotetext{
${ }^{2}$ The experts that were asked to review the scenario were either manager or experienced employees (over 10 years of experience) in the electricity trading sector.

${ }^{3}$ The values that the participants could attribute to the frequency of interaction included: Never $=0$ Yearly interaction $=1$ Twice a year interaction $=2$ Monthly interaction $=3$ Weekly interaction $=4$ Daily interaction $=5$ Near real-time interaction $=6$. In this survey, interaction was classified as a broad concept and could include interaction in terms of transfer of either knowledge, data, technology or financial resources.

${ }^{4}$ The participants were asked for each line they drew to explain why they thought the frequency of the interaction would change, providing a rich understanding of the new interactions in the future actor configuration.
} 
gleaned to analyze the structure and patterns of the relationships between the system actors. First, two properties were obtained that measure the overall structure of a network: the shape and density. The network shape refers to the morphology of a network and the overall distribution of the ties in the network, which can be used to differentiate the core actors (that are highly connected) in the network from the actors in the periphery (with few connections) [58]. Network density is a metric that is often used in network research to examine the degree of interaction within a system [59]. It refers to the measure of cohesiveness within a network. Density was calculated according to Formula (1). It is the proportion of the number of ties in the network relative to the total number of possible ties. The $T$ in this formula refers to the number of existing ties in the network and $n$ is the number of nodes in the network.

$\frac{T}{n(n-1) / 2}$

\subsubsection{Node-level metrics (quantitative SNA)}

Next, additional metrics were computed to gain insights per individual network actor, including betweenness centrality, eigenvector centrality and the degree. Betweenness centrality measured the extent to which a specific actor is an intermediary. The intermediary position determines how much information and other resources flow through a certain node. The higher the degree, the more important the intermediary role of the actor and the more central the actor is in the network, since more resources flow through this node. Betweenness centrality was calculated according to Formula (2), with $g_{i j}$ as the number of shortest paths connecting actor $a_{i}$ and $g_{i j}\left(a_{k}\right)$ representing the paths connecting $a_{i}$ and $a_{j}$, containing actor $a_{k}$.

$\sum_{i<j} \frac{g_{i j}\left(a_{k}\right)}{g_{i j}}$

Eigenvector centrality is a metric that measures the influence of a node in a network. It measures how important a node is by measuring how important the other nodes are that are connected to that specific node, in terms of centrality. This implies that if a node has a high eigenvector score, it is connected to many other nodes with high scores. Formula (3) describes how the eigenvector centrality was calculated for a network $G:=(V, E)$ with $|V|$ vertices let $A=\left(a_{i, t}\right)$ be the adjacency matrix. That means that $a_{v, i}=1$ if vertex $v$ is linked to vertex $t$, and $i=0$ if not.

$C_{E}\left(n_{i}\right)=\frac{1}{\lambda} \sum_{t \in M\left(n_{i}\right)} C_{E}\left(n_{t}\right)=\frac{1}{\lambda} \sum_{t \in G} a_{i, t} C_{E}\left(n_{t}\right)$

Degree is an indicator of the number of ties that are connected to a node. The degree is the simplest way to measure the influence of a node in a network: generally, nodes with a high degree have more influence. In this SNA we used the degree to support the overview depicting the new actor functions that was constructed by means of the qualitative SNA.

\subsubsection{Tie-level metrics (qualitative SNA)}

The tie-level metrics focused on the context of the ties in the network. The strength of the relation is a measure to indicate the strength of the relationship between two nodes in the network. This measure is a visual property rather than a property indicating a quantity, and it was indicated in the visually depicted network by the width of the ties. This property was only valuable if it was supported by the new functions that came forward during the qualitative SNA. The overview depicting the new actor functions explained how the network members perceived the relationships, thereby providing insights in the content and the meaning of the ties.

\section{Results}

In this section we present the results of our research. We first describe the dynamics and actor configuration in the current Dutch electricity system (4.1), followed by a description and analysis of the potential actor configuration in the future system based on an explorative, normative scenario (4.2). The focus in the later part is in on the potential change of the actor configuration when blockchain is introduced.

\subsection{Actor configuration in the current Dutch electricity system}

\subsubsection{Current dynamics (2005-2018)}

Several landscape developments have influenced and are still influencing the Dutch electricity system. These are in particular climate change and the need to reduce GHG emissions. Next to this, there are several general trends that have an impact on the system: the increasing demand for electricity, the emergence of distributed generation and digitalization. In the coming decades digital technologies and the strategic use of data will be at the core of new energy innovations [60-62]. According to a recent Bloomberg study, the focus of innovation in the energy industry will shift from a focus on hardware to a focus on software to make the electricity system more resilient, efficient, intelligent, digital and sustainable [22].

Institutional changes in the electricity system have been triggered by the surge of neo-liberalism and the optimism about the process of European integration in the 1990s. In 1998, the Dutch parliament adopted an electricity bill for the liberalization of the electricity market. One of the main consequences was the unbundling of the generation and retail function from the transmission and distribution of electricity. By now, the utilities without their grids have been bought by international energy companies, while the network companies have remained in public hands. Also, all kind of new actors emerged on the scene, like utilities offering only 'green' electricity and many local cooperatives. The process of reconfiguration in the electricity sector is still ongoing. Recent policy issues for example focus on the role of aggregators of distributed generation providers on the market and the need or desirability to enable peer-to-peer electricity exchange and the creation of LEMs.

Overall, the Dutch electricity system has become technologically and socially more complex and the complexity will only further increase in the future. This explains the attractiveness of the blockchain technology, as it both promises to deal with the data and to completely transform the actor configuration in the electricity system. The most common current applications of blockchain in this sector include utility billing [63], certificates of origin tracking [64], demand response management [65] and local electricity trading [55].

\subsubsection{Current actor configuration}

The dynamics in the electricity system explained above gave rise to the formation of various novel actors in the electricity system. This section gives an overview of the current most important actors, their interrelatedness with each other and their functions in the existing electricity system.

The first actor group that is essential in the electricity system 
encompasses electricity producers (and to a lesser degree also prosumers). They are responsible for the generation process in the system. Most of the producers in the Netherlands generate electricity at nuclear or fossil-fueled power plants, although the input from renewable resources is increasing. These producing companies may or may not be part of larger energy companies. The electricity that they produce is often sold directly to the grid and for that reason producers are in direct contact with grid operators, who communicate to producers the amount of electricity they need for grid balance.

To sell the power to the grid, producers often make use of electricity marketplaces, which are operated by the market operator. Via the market operator (mainly the Epex Spot for the Netherlands) electricity can be sold to either large consumers, traders or suppliers (who in turn deliver it to small and medium sized consumers). The market operator is responsible for the organization and administration of trade in electricity and payment settlements among producers, suppliers, and customers, and for the creation of transparent price signals. Moreover, they ensure delivery and payment of those transactions.

For a properly functioning grid it is essential that electricity can securely be transported over long distances and that the balance between electricity supply and demand is maintained. The Transmission System Operator takes care of this by operating and maintaining the high-voltage grid. In the Netherlands, there is only one transmission system operator, namely TenneT. This actor is responsible for the transmission process of electricity, the management the transmission network, the import capacity and the balancing of the grid.

To balance the grid however, the transmission system operator cannot operate on its own. The transmission system operator must communicate with various parties to regulate the inflow of electricity and balancing, for example with producers and with the distribution system operator for network management. Also, the transmission system operator must communicate with the Balance Responsible Party/Trader to anticipate on how much electricity each party connected to the grid is going to feed into and take out of the grid. A balance responsible party is responsible for balancing the acquisition and sales volume of electricity and the planning of the daily usage. Balance responsible parties must present their e-programs at the end of the day to the transmission system operator to enable grid balancing, whereas traders do not as they only buy and sell power and do not carry the price risk.

Where the transmission system operator is responsible for the operation of the high voltage grid, the Distribution System Operator is responsible for providing and operating low and medium voltage grids for the regional distribution of electricity. Furthermore, the distribution system operator is responsible for voltage control and reactive power management within the grid. Because of these responsibilities distribution system operators must communicate and interact with various other actors, for example with metering companies for updates on electricity consumption of large-scale consumers; with market service providers/ charge point operators for electricity flow to charging stations; and with balance responsible parties/traders to distribute the electricity that is bought on the electricity market.

A straightforward, yet essential, actor in the electricity system are the consumers and prosumers. They are the final actors in the process of electricity supply, as a consumer is an individual who buys and uses electricity, whereas a prosumer both buys and produces electricity, for example through privately owned rooftop solar panels. Consumers can be categorized in large-scale consumers (i.e. with connections bigger than $3 \times 80 \mathrm{~A}$ (ca $100.000 \mathrm{kWh}$ )) or medium-scale to small-scale consumers (i.e. with connections smaller than $3 \times 80 \mathrm{~A}$ ).

Since producers often sell their electricity to the marketplace and therefore not directly to small-scale and medium-scale consumers, these consumers need another actor to purchase their electricity from: suppliers. Suppliers primarily interact with the market operator for the procurement of electricity, with the data facilitator to communicate actual consumption data, and of course with the end consumer, as the supplier delivers electricity to the (small or medium sized) consumer or prosumer.

From the moment of the unbundling in the 1990s, several new actors appeared on the scene. One of them is the data facilitator that emerged in response to the growing amount of data between the increasing number of actors in the Netherlands, called 'Energie Data Services Nederland' (EDSN). The data facilitator expedites the administrative data exchange between market parties, such as system operators, metering companies, balance responsible parties and suppliers. Furthermore, the data facilitator safeguards free market processes and enables an administrative platform for consumers and suppliers which enables the switching of suppliers for consumers.

The metering company is another new actor, who is in close contact with the data facilitator. The metering companies used to be part of the grid operators but have now become separate entities. They supply, install and maintain the electricity and gas meter, collect power and gas consumption data and send it to the data facilitator.

The growing need for flexibility in the grid gave further rise to $a g$ gregators. Aggregators have the capacity to manage demand response and offer technical or economic services to electricity actors. They allow flexible management of the grid by rewarding consumers who are connected to the grid for low energy usage at peak times.

Moreover, among the newest actors are Charge Point Operators, responsible for the delivery, instalment and maintenance of charging points for electric vehicles, and Mobility Service Providers responsible for the commerce of mobility products and services for electric vehicles including payments and subscriptions for vehicles charging. Since both actors mostly fulfill both the roles (of charge point operator and market service provider), this article combines the two roles into one actor group.

Lastly, there are several national and international actors, who should supervise and regulate the national and international electricity market, but who are not yet active in the market. The responsible actor for protecting national consumer interests and safeguarding a competition-friendly market is the Authoriteit Consument en Markt (ACM). A key international (European) regulatory body is the European Network of Transmission System Operators for Electricity (ENTSO-E). The ENTSO-E is a network of European transmission system operators and currently represents 43 in total. Their aim is to set up a strong European internal energy market and support the European energy and climate agenda. The Agency for the Cooperation of Energy Regulators (ACER) is a new actor who ensures the proper functioning of the European gas and electricity market by supervising and coordinating regulatory decisionmaking processes at national and European level.

\subsection{Potential actor configuration in the future Dutch electricity system}

\subsubsection{Potential dynamics based on a normative scenario (2030)}

In 2030 energy is produced mainly in a decentral manner. Every household in the Netherlands generates its own electricity or buys it from small-scale and local producers, such as farmers owning a wind turbine, or from neighbors and other community members with solar panels on their roofs.

In this scenario, there will be multiple blockchain platform(s) enabling small-scale participants, such as SME companies, consumers and prosumers, to trade electricity with each other (peer-to-peer trading). This will happen on local energy markets, where consumers and prosumers will be 
Table 1

Summary of the network metrics and their visible network properties.

\begin{tabular}{lll}
\hline Level & Metric & Visible network property \\
\hline Overall-level & Network shape & $\begin{array}{l}\text { Morphology of the network } \\
\text { Cohesiveness of the network }\end{array}$ \\
Node-level & Network density & Size of the node \\
& Betweenness centrality & N.A. \\
Tie-level & Eigenvector centrality & Width of the tie \\
& Strength of the relation & Number of connections \\
& Degree & \\
\hline
\end{tabular}

able to trade within their community, facilitating (near) real-time pricing and a local balance of supply and demand. The local markets are smart, decentralized and interconnected markets, and will connect consumers and prosumers via either microgrids or virtual power plants. Hence, the most significant institutional change will be the legitimation of trading within LEMs, which strengthens the positions of the prosumer.

Each household will be equipped with a battery and a smart meter, enabling bilateral trade of the electricity stored on the battery. The blockchain-based trading platform will facilitate automatic local (micro) transactions via algorithms that trade on behalf of the consumers via personalized smart contracts set in the blockchain. These contracts could include options where users can choose the type and origin of their electricity, in a dynamic manner and based on their personal preferences. Moreover, the smart contracts set in the blockchain will facilitate machine-to-machine communication for devices at home. The devices will be connected to the grid via a smart meter (or plug) and will autonomously charge or start at the exact moment that it is most profitable for both the user and the grid.

\subsubsection{Potential future actor configuration vs existing actor configuration}

Each of the networks is characterized by six network metrics and their accompanying visible network properties (if applicable), summarized in Table 1.

The network presented below in Fig. 2 depicts the actor configuration of the current system. For the remainder of this analysis, the network is contrasted with Fig. 3, which depicts the potential future actor configuration based on the interpretations of the research participants of the normative scenario described in Section 4.2.

Each network node represents an actor group as defined in Section 4.1 and each tie represents a connection between two nodes. The corresponding network metrics that aim to support the interpretation of the visualized networks are displayed in Tables 2 and 3. Although more data is available concerning the position of each node, only the most diverging values are depicted in the table.

\subsubsection{Overall-level metrics (quantitative SNA)}

The overall-level metrics provide insights in the general structure of the network and include the network shape and density. The network shape refers to the distribution of nodes and ties across the network and can be useful to distinguish the core actors (i.e. the highly connected nodes) in the network. In the existing network (Fig. 2) we observe that the network core includes at least six actors, whereas the remaining actors are clearly positioned in the periphery of the network. In contrast, the future network depicts a more diffused and less centralized network with only four core actors and more nodes that have moved to the periphery of the network. When comparing the network density between the two networks, the future network depicted in Fig. 3 appears denser than the existing network in Fig. 2. The metrics in Table 2 confirm this assumption and indicate that the network density has risen from 0,691 (Fig. 2) to 0,745 (Fig. 3), signifying that $74,5 \%$ of all ties that could theoretically be existent in the network are indeed realized. This means that there are more relations in the future network than in the existing network, indicating a potential overall increase in collaboration and interaction between actors in the future network.

\subsubsection{Node-level metrics (quantitative SNA)}

The node-level metrics provide a deeper understanding of the separate nodes and enable the identification of actors that stand out in terms of the network metrics. The node-level network metrics that are

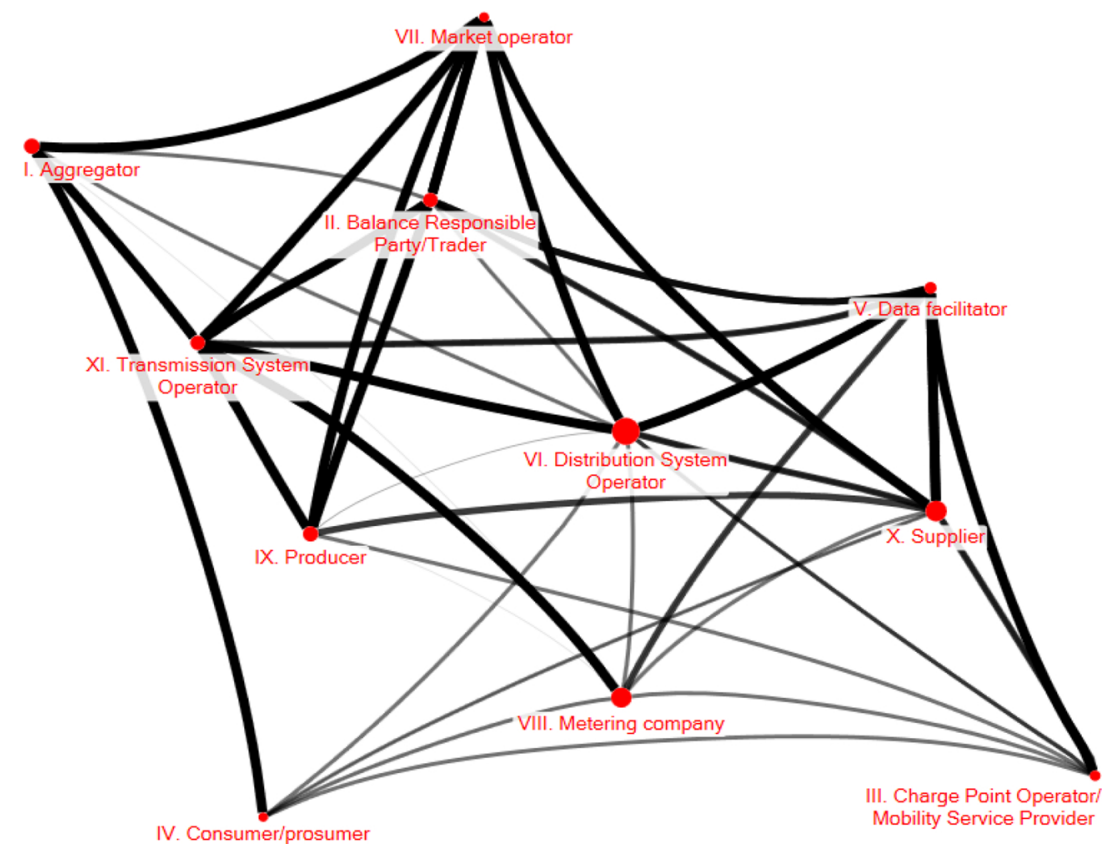

Fig. 2. Actor configuration in the existing electricity system (dark and bolt lines indicate frequent interaction, light and thin lines indicate non-frequent interaction). 


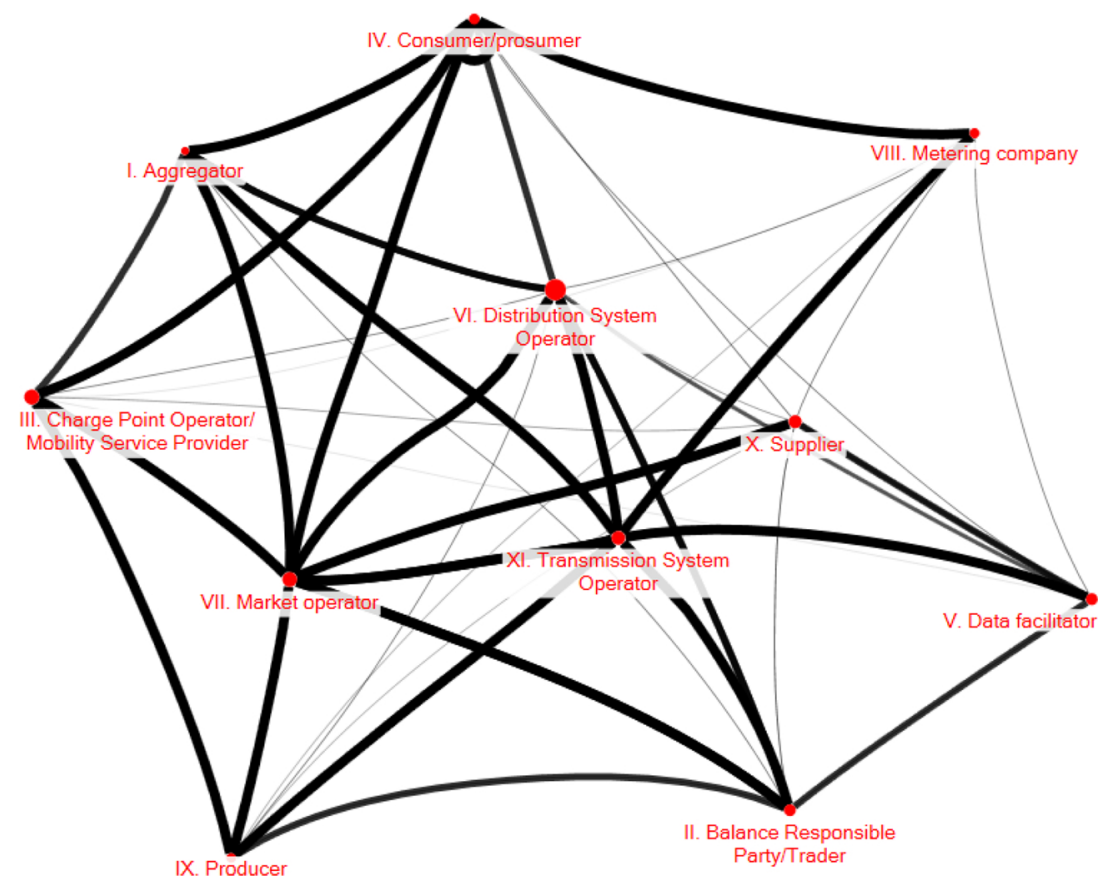

Fig. 3. Actor configuration in the future electricity system (dark and bolt lines indicate frequent interaction, light and thin lines indicate non-frequent interaction).

Table 2

Network metrics to support the visualized networks.

\begin{tabular}{|c|c|c|}
\hline Metric & Existing network & Future network \\
\hline Network density & 0,691 & 0,745 \\
\hline \multirow[t]{3}{*}{ Highest betweenness centrality } & Distribution system operator $(4,267)$ & Distribution system operator $(2,650)$ \\
\hline & Supplier $(2,533)$ & Charge point operator/Mobility service provider $(1,550)$ \\
\hline & Metering company $(2,400)$ & Transmission system operator $(1,350)$ \\
\hline \multirow[t]{3}{*}{ Highest eigenvector centrality } & Distribution system operator $(0,123)$ & Distribution system operator $(0,115)$ \\
\hline & Metering company $(0,102)$ & Consumer/prosumer $(0,098)$ \\
\hline & Supplier $(0,102)$ & Supplier $(0,097)$ \\
\hline \multirow[t]{3}{*}{ Highest degree } & Distribution system operator (10) & Distribution system operator (10) \\
\hline & Metering company/supplier (8) & Consumer/prosumer (9) \\
\hline & $\begin{array}{l}\text { Transmission system operator /producer/balance responsible } \\
\text { party/trader (7) }\end{array}$ & $\begin{array}{l}\text { Charge point operator / Mobility service provider /market operator/ } \\
\text { supplier (8) }\end{array}$ \\
\hline \multirow[t]{3}{*}{ Lowest betweenness centrality } & Consumer/prosumer $(0,533)$ & Aggregator $(0,733)$ \\
\hline & Market operator $(0,567)$ & Producer $(0,867)$ \\
\hline & Charge point operator / Mobility service provider $(0,667)$ & Metering company $(0,900)$ \\
\hline \multirow[t]{3}{*}{ Lowest eigenvector centrality } & Consumer/prosumer $(0,068)$ & Aggregator $(0,074)$ \\
\hline & Aggregator $(0,079)$ & Transmission system operator $(0,082)$ \\
\hline & Charge point operator / Mobility service provider $(0,081)$ & Balance responsible party/trader $(0,083)$ \\
\hline \multirow[t]{3}{*}{ Lowest degree } & Consumer/prosumer (5) & Aggregator (6) \\
\hline & $\begin{array}{l}\text { Aggregator/ Charge point operator / Mobility service provider } \\
\text { /data facilitator/market operator (6) }\end{array}$ & $\begin{array}{l}\text { Balance responsible party/trader/data facilitator/ metering company/ } \\
\text { producer /transmission system operator ( } 7 \text { ) }\end{array}$ \\
\hline & $\begin{array}{l}\text { Transmission system operator/producer/balance responsible } \\
\text { party/trader (7) }\end{array}$ & $\begin{array}{l}\text { Charge point operator / Mobility service provider /market operator/ } \\
\text { supplier (8) }\end{array}$ \\
\hline
\end{tabular}

analyzed in this SNA include the betweenness centrality and the eigenvector centrality.

Both networks depict another visual property that represent a network metric: the sizes of the nodes. The size of the nodes is proportional to the betweenness centrality of the actors: the larger the diameter of the node, the higher the degree of betweenness of the node in the network. This measure indicates the extent to which an actor lies on the path between two actors in the network, and therefore measures the extent to which an actor functions as an intermediary. Compared to the existing network, the nodes in the future network seem to be more similar in size to one another and thus appear to be more homogenous in terms of size. Since the sizes of the nodes represent the betweenness centrality, this means that the betweenness centrality of the nodes in the future network have become more similar to each other. As Table 2 shows, the betweenness centrality values are indeed less scattered: the range of the values for the current network is larger $(0,533 \leq$ betweenness centrality $\leq 4,267)$ than the values for the future network $(0,733 \leq$ betweenness centrality $\leq 2,650)$, indicating that there are fewer actors with either a strong or a weak brokerage position. The overall level of centralization is therefore lower in the future network than in the current network. This illustrates that blockchain in this sense could indeed lead to a slightly more distributed network than the 
current network. The actor with the highest betweenness centrality is the distribution system operator (VI), with the highest value in both the existing and the future network. This means that the distribution system operator has an important strategic position in both networks as bridging actor for the flow of resources through the networks, although this strategic position is likely to decrease (from 4,267 to 2,650 ) a bit according to the metrics. However, even though the distribution system operator remains the actor with the strongest intermediary position, changes are expected for the other actors. In the future network, the supplier (X) and metering company (VIII) no longer have the highest betweenness centrality values. Instead, their positions as strong intermediaries are replaced by the charge point operator/market service provider (III) and the transmission system operator (XI). This means that the amount of resources flowing through these actors is likely to shift, with the supplier and the metering company facing a decrease of resources flow through and the charge point operator/market service provider and the transmission system operator an increase of resources flowing through. Regarding the lowest betweenness centrality values, the intermediary position of the charge point operator/market service provider shows the strongest rise in the future network as the charge point operator/market service provider shifts from one of the actors with the weakest intermediary position towards one of the strongest intermediary positions. Furthermore, the intermediary position of the consumer/prosumer and the market operator are likely to increase, while the aggregator and the producer are likely to see the amount of resources flowing through decrease.

The last node-level metric is the eigenvector centrality, which is used to indicate the influence or the importance of an actor in the network. This metric is not visually depicted in the networks and can merely be analyzed via Table 2. In the existing network, the highest eigenvector centrality can be attributed to the distribution system operator and is followed by the metering company and the supplier. This implies that the distribution system operator is the most influential and important node in the existing network, meaning that it is important because it is surrounded by other nodes which are important (i.e. have a high eigenvector centrality). In the future network however, the eigenvector centrality values have changed. Although the distribution system operator and the supplier retain their high eigenvector centrality value, the metering company loses its high level of influence to the consumer/prosumer, which becomes more important in the future network. This also means that the consumer/prosumer is no longer the least important actor. In the existing network, the consumer/prosumer together with the aggregator and the charge point operator/market service provider, were considered to be the least important actors. Instead, the lowest positions are now taken by the aggregator, the transmission system operator and the balance responsible party/trader.

\subsubsection{Tie-level metrics (qualitative SNA)}

The tie-level metrics are useful to provide more information on the changes in the degree and the strength of the relation. The degree refers to the number of incoming as well as outgoing connections of an actor and is useful to identify the core actors in a network. The strength of the relation is a network property that cannot be quantified and depicted in a table but can only be observed in the visualized networks. Furthermore, the strength of the relation and degree can only be fully understood by means of the evolution of functions, which is summarized in Section 4.3. The connections between the actors, which are represented by the ties between the nodes, are either in terms of transfer of knowledge, data, technology or financial interactions. The ties vary from each other in darkness of opacity and width, which indicate the strength of the connection between two nodes. The darker and wider (or thicker) the tie is, the stronger the connection between the two nodes. By combining the tie-level metrics with insights gathered from the qualitative SNA, they provide a narrative that is useful to support and understand the node-level metrics.

The existing network shows specifically strong connections in the upper half of the network. The positive outliers in this respect are the market operator (VII) and the transmission system operator (XI), which appear to have merely very strong relations with the actors they are connected to. This confirms our prior understanding that the transmission system operator and market operator have a strong platform function for its interconnected nodes in terms of physical processes which are directly related to the value chain of the electricity system. Moreover, the balance responsible party/trader (II) and the data facilitator (V) have various strong relations with their connected nodes, which indicates that these nodes interact closely with their surrounding nodes. Other nodes that have many and strong relations in this network are the supplier (X) (degree of 8) and the metering company (VIII) (degree of 8), which puts them in a central position in the network. The negative outliers in this current network are the charge point operator/ market service provider (III) and the consumer/prosumer (IV), which both appear to have only one strong connection and several weak connections. Furthermore, the consumer/prosumer also has very little connections (degree of 5) and is located at the periphery of the network, illustrating and confirming our prior knowledge that currently the prosumer/consumer is not a central actor in the network and has little resources flowing through.

In the future network, one can observe that the market operator (VII) still has many ties, which is like its number of ties in the current network. However, in the future network the market operator has a more central position and has a higher degree ( 8 vs 6 ) than in the previous network. This illustrates that in the new network the market operator is likely to play a more central role in the trading of electricity among peers within local energy communities. Other nodes which are in a central position in the network are the transmission system operator (XI) and the distribution system operator (VI). Similar to the current network, in the future network the transmission system operator has the same number of ties (degree of 7) and has merely strong relations with its connected nodes. This indicates that the transmission system operator will remain an important actor in the future network. Nonetheless, although the distribution system operator also still has the same number of ties, the strength of the ties appears to have diminished. It is still in a central position in the network, which indicates that it is still in a critical brokerage position in the network. Another observation in the future network is the diminished number of strong relations of the balance responsible party/trader (II) and the data facilitator (V). This indicates that in the future electricity system, the balance responsible party /trader and the data facilitator could perform different roles for the actors that currently have relations with the balance responsible party /trader and the data facilitator, which will require less strong interactions. Another key observation that stands out in the future network, is the strong increase in number of ties of the consumer/prosumer (IV) (9 in the future network vs 5 in the current network).

\subsection{Evolution of actor functions and positions}

To answer the research question of this article, we not only investigate the expected novel interactions, but we also use them to explain how the functions of the actors could change in a future blockchain-based electricity system. There are several ways in which the introduction of blockchain might influence the actor configuration in the electricity system. Therefore, to support the network metrics, a qualitative SNA was conducted, providing an overview that explains and accounts for the changes in the two networks . 
Table 3

Overview of the expected function shifts within the electricity system.

\begin{tabular}{|c|c|c|}
\hline Actor & Future function & Future network position \\
\hline Aggregator & $\begin{array}{l}\text { Lots of uncertainty, however, three options emerged: } \\
\text { 1) Aggregators could disappear: blockchain could take over their role; } \\
\text { 2) The supplier or the balance responsible party /trader could take over } \\
\text { and incorporate the current role of the aggregator. } \\
\text { 3) Similar function as in the current system but will become more } \\
\text { important overall. }\end{array}$ & $\begin{array}{l}\text { Will have a declined broker position and less influence in the } \\
\text { network. There is, however, lots of uncertainty. }\end{array}$ \\
\hline $\begin{array}{l}\text { Balance responsible party/ } \\
\quad \text { trader }\end{array}$ & $\begin{array}{l}\text { No radical changes expected for its main functions. However, the function } \\
\text { of the balance responsible party/trader could become more similar to and } \\
\text { intertwined with the current role of the aggregator. }\end{array}$ & $\begin{array}{l}\text { Will have a declined broker position and less influence in the } \\
\text { network. Shift in position is related to position shift of the } \\
\text { aggregator. }\end{array}$ \\
\hline $\begin{array}{l}\text { Charge point operator/ market } \\
\text { service provider }\end{array}$ & $\begin{array}{l}\text { Same function. However, likely to become more important for two } \\
\text { reasons: } \\
\text { 1) Market share of electric vehicles will be significantly higher; } \\
\text { 2) EVs could become important assets for flexibility services providers. }\end{array}$ & $\begin{array}{l}\text { Will have an increased broker position and will have more influence } \\
\text { in the network. }\end{array}$ \\
\hline Consumer/ prosumer & $\begin{array}{l}\text { Several possibilities emerged: } \\
\text { 1) This actor could become more self-supportive; } \\
\text { 2) The reciprocal interactions between consumers/prosumers are likely } \\
\text { to increase; } \\
\text { 3) Their function is likely to shift more to the current function of } \\
\text { suppliers and producers; } \\
\text { Hence, they will be able to compete with suppliers and producers for } \\
\text { supplying electricity. }\end{array}$ & $\begin{array}{l}\text { Will have a more influential position due to an increase in various } \\
\text { interactions. However, they will still depend on suppliers and } \\
\text { producers, so their current function will not change as radically as } \\
\text { some may suggest. }\end{array}$ \\
\hline Data facilitator & $\begin{array}{l}\text { Two optional shifts are expected: } \\
\text { 1) The data facilitator could become obsolete; } \\
\text { 2) They could become responsible for the taxing of peer-to-peer trading } \\
\text { (for making use of the grid) and could become the main responsible } \\
\text { party for supervising all fiscal aspects concerning LEMs }\end{array}$ & $\begin{array}{l}\text { Will still be important as an intermediary and will remain a relatively } \\
\text { influential and important node. }\end{array}$ \\
\hline Distribution system operator & $\begin{array}{l}\text { Again, there are several options: } \\
\text { 1) The distribution system operator could become (jointly) responsible } \\
\text { for the balancing of the local grid (the LEMs) while the transmission } \\
\text { system operator will remain responsible for the national grid. } \\
\text { 2) Blockchain could replace the distribution system operator for } \\
\text { congestion management and automate flexibility services by } \\
\text { automatically connecting local aggregators (e.g. EVs or home } \\
\text { batteries) to each other. Consequently, the distribution system } \\
\text { operator could become responsible for the management and } \\
\text { supervision of blockchain development. }\end{array}$ & $\begin{array}{l}\text { Will have a decreased position as an intermediary and decreased } \\
\text { influential position, yet these values will still be relatively high. }\end{array}$ \\
\hline Market operator & $\begin{array}{l}\text { No radical shift is expected, but its focus could shift towards local markets. } \\
\text { It could for example provide a platform that could connect the consumer/ } \\
\text { prosumer to directly access the wholesale market. }\end{array}$ & $\begin{array}{l}\text { Will become more influential and more important as an intermediary } \\
\text { because in its future function it is likely to be more open to other } \\
\text { actors willing to trade electricity. }\end{array}$ \\
\hline Metering company & $\begin{array}{l}\text { The function of the metering company could shift towards service } \\
\text { provision of the advanced smart meters/plugs to the consumers/ } \\
\text { prosumers. }\end{array}$ & $\begin{array}{l}\text { Will have a substantially weaker intermediary position yet will still } \\
\text { be relatively important. }\end{array}$ \\
\hline Producer & $\begin{array}{l}\text { Not much change is expected, as producers will still be important in times } \\
\text { of local energy scarcity. However, the demand for producers will be less } \\
\text { high and less frequent due to increased self-sufficiency of con-/prosumers. }\end{array}$ & Will drop in intermediary position and importance, yet negligible. \\
\hline Supplier & $\begin{array}{l}\text { Three different possibilities: } \\
\text { 1) They will become obsolete: electricity could be bought directly from } \\
\text { producers via a blockchain enabled trading platform; } \\
\text { 2) Their roles will intertwine with the current role of the aggregator (and } \\
\text { possibly the balance responsible party/trader); } \\
\text { 3) Suppliers will still be needed in case of local electricity shortages. }\end{array}$ & $\begin{array}{l}\text { Will have a decreased intermediary position yet will have same the } \\
\text { level of influence. }\end{array}$ \\
\hline $\begin{array}{l}\text { Transmission system } \\
\quad \text { operator }\end{array}$ & $\begin{array}{l}\text { Two options came forward: } \\
\text { 1) Transmission system operators will still be essential in the future, } \\
\text { since the trans-European transmission will still be required in this } \\
\text { scenario. However, the amount of electricity could decrease; } \\
\text { 2) The functions of the transmission system operator and the distribution } \\
\text { system operator could become more intertwined (distribution system } \\
\text { operators could become responsible for balancing the local grids) }\end{array}$ & $\begin{array}{l}\text { Will increase in intermediary position yet will be less important due } \\
\text { to decreased use of the transmission grid. }\end{array}$ \\
\hline
\end{tabular}

During the network drawing picture exercise, the research participants were asked whether they thought a new function could emerge in the future electricity system. All eleven research participants answered that it was be likely that a new function would emerge in this pathway, namely the function of controlling and operating the blockchain platform. For a blockchain to function, advanced algorithms are required to facilitate local trading. The blockchain operator could become the actor that oversees the generation and optimization of the algorithms on the blockchain. Hence, a new actor or an existing actor would in this case become responsible for the development of the ICT infrastructure that will be needed to enable this pathway. In this study, it remains unclear whether the future blockchain-based electricity system requires one large blockchain platform or a patchwork of smaller blockchain platforms operating next to each other. Ergo, the question remains as to which actor(s) would become responsible for these roles in the future electricity system, or whether an entirely novel actor with central authority would arise in the electricity system.

Moreover, as Table 3 points out, there are various uncertainties regarding the future functions of existing system actors since existing actors could get different renewed functions. Nevertheless, despite this uncertainty Fig. 4 provides the visualization of a potential future (blockchain-based) electricity system, which is based on our quantitative and qualitative findings. In this visualization we strongly build and aim to extend the analysis of Verbong and Geels [66] where the 

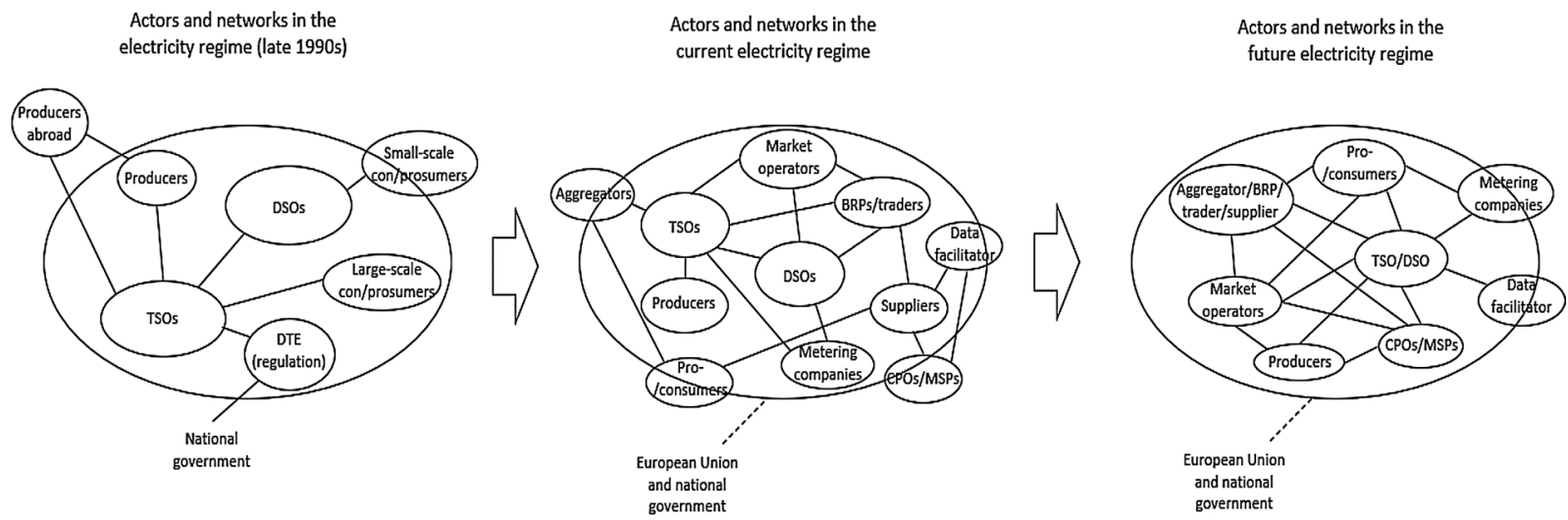

Fig. 4. Actors in the existing electricity system and the potential evolution of the system in a blockchain-based electricity system.

developments of the Dutch energy system were mapped from its early years of existence 1960 till 2004 [66].

As Fig. 4 shows, the number of actors in the current and future electricity system increases considerably, and their interconnectedness increases likewise. Since the current system has more actors and interrelationships, there is more mutual interdependence between system actors than in the 1990s. As the socio-technical analysis in Section 4.1 pointed out, various novel functions have come into existence only in the 1990s and early $00 \mathrm{~s}$ and are therefore considered new. One of the general outcomes of this study is that the implementation of a radical niche technology, such as blockchain, is likely to have a difficult time in being translated to practices in the electricity system. The unbundling and liberalization in the $90 \mathrm{~s}$ thus seem to have created a more complex landscape with scattered responsibilities and ongoing evolving functions. Consequently, the rise in the number of actors in the current system poses challenges to the adoption and implementation of blockchain in the electricity system as more actors will need to adopt and implement blockchain than in a system with fewer actors. As for the potential future electricity system, the pathway that came forward in our analysis is displayed in Fig. 4. The last system depicts the actor configuration that has come forward by means of the qualitative and the quantitative SNA performed in this chapter. It depicts a system in which several functions are intertwined with each other, hence depicting a more 'homogenous' system including more hybrid actors. Due to the homogenous nature of this system, it is possible that deviations from the depicted system will occur in the future, since different combinations of functions could constitute the future system.

\section{Discussion and conclusion}

Over the years, transition studies have focused strongly on the disruptive power of 'typical green technologies' on the existing electricity system. Meanwhile, the role of digital technologies in the energy transition did not receive much attention. The main contribution of our research is that it adds to the existing transition studies by providing more insight in the effect of a disruptive digital technology, blockchain, on the energy transition. By focusing on how blockchain can influence the actor configuration in the Dutch electricity system this article goes beyond pure technological focus and its limitations [67]. Our results indicate that the influence of the blockchain technology on the functions within an existing system can be significant, yet it is not likely to be as disruptive and decentralizing as may be suggested in the mass media. The results showed that many functions are likely to remain and that new central authorities may be formed, such as the blockchain operator. This research therefore sheds a new light on the ongoing discussion about the potential of blockchain to disrupt and reshape the electricity system. It provides evidence that it is unlikely for blockchain to lead to the full abolition of intermediary actors within the electricity system since intermediary actors are likely to either remain necessary or to see their current functions change.

Furthermore, since our study showed that blockchain could lead to the formation of novel functions with a central authority position (i.e. a central blockchain operator), this research offers a new perspective to the potential of blockchain for all electricity system actors. In future literature, we feel that it is fair to say that blockchain should be considered as a technology that opens opportunities for all system actors to reconsider their existing roles rather than as a technology that threatens them. Moreover, an important conclusion that can be drawn from our results is that, despite the high expectations of people of blockchain's ability to lead to optimize transaction processes and create a more efficient system, it is not a panacea. It could even lead to new problems, such as centralization of power around blockchain operator.

Our research adds to the work of Geels and Verbong (2007) as it provides an update of the current Dutch electricity system by showing that the electricity system is still in flux ten years after the publication of their article. Our article points out that the emergence of distributed generation, the increasing demand for electricity and the rise of digitalization are putting pressure on the current electricity system, creating an electricity system in transition. Lastly, the combined use of a transition lens with a social network analysis as an analytical approach in this study contributes to the further development of the transition study field, since the approach can be used for future studies to investigate the expected influence of new technologies on the actor configuration within a system. Combining the connectionist view with the structuralist view hereby offers added value as it enables a complete approach to analyze the networks of actors within a socio-technical system.

It is important to clarify that in this explorative exercise we investigated one of many possible futures where several combinations of functions are possible. Still this one possible future pathway showed that various variations of configurations could arise, indicating the exploratory nature of this research. Furthermore, although substantial insights have been gained, it is fair to notice that various topics have been left untouched in this research. For that reason, in future research it could be interesting to study:

- The specific influence of certain function combinations on the actor configuration;

- The influence of blockchain on the tasks and functions of supervisory bodies in the future;

- The feasibility and the affordability of a blockchain-based peer-topeer electricity system.

\section{Acknowledgements}

This article was made possible with support from Interreg NWE project 588 on Community-based Virtual Power Plant (cVPP): a novel model of radical decarbonisation based on empowerment of low-carbon 
community driven energy initiatives. The authors would also like to thank interviewees who participated in the study, Rudi Bekkers for suggesting network drawing exercises, Eneco for facilitating the graduation project that formed the incentive for this paper, three anonymous reviewers and the editor for their constructive feedback on earlier versions of the paper.

\section{References}

[1] N. Abas, A. Kalair, N. Khan, Review of fossil fuels and future energy technologies, Futures 69 (2015) 31-49, https://doi.org/10.1016/j futures.2015.03.003.

[2] A. Wieczorek, F. Berkhout, Transitions to sustainability as societal innovations, in: L. Boersema, J. Reijnders (Eds.), Principles of Environmental Sciences by Boersema, J. \& Reijnders, L. Springer International Publishing, 2009, pp. 503-512, , https:// doi.org/10.1007/978-1-4020-9158-2 23.

[3] C. Pop, T. Cioara, M. Antal, I. Anghel, I. Salomie, M. Bertoncini, Blockchain based decentralized management of demand response programs in smart energy grids, Sensors 18 (1) (2018) 162, https://doi.org/10.3390/s18010162.

[4] A. Castillo, D.F. Gayme, Grid-scale energy storage applications in renewable energy integration: a survey, Energy Convers. Manage. (2014), https://doi.org/10.1016/j. enconman.2014.07.063.

[5] J. Green, P. Newman, Corrigendum to "Citizen utilities: the emerging power paradigm", Energy Policy 105 (2017) 283-293, https://doi.org/10.1016/j.enpol. 2017.04.036.

[6] A. Hope, T. Roberts, I. Walker, Consumer engagement in low-carbon home energy in the United Kingdom: implications for future energy system decentralization, Energy Res. Soc. Sci. 44 (2018) 362-370, https://doi.org/10.1016/j.erss.2018.05. 032.

[7] J.Y. Yong, V.K. Ramachandaramurthy, K.M. Tan, N. Mithulananthan, A review on the state-of-the-art technologies of electric vehicle, its impacts and prospects, Renewable Sustainable Energy Rev. 39 (2015) 365-385, https://doi.org/10.1016/j. rser.2015.04.130.

[8] Ewea, Wind in power - 2015 European Statistics, 2015 European Statistics (2016), https://doi.org/http://www.ewea.org/fileadmin/files/library/publications/ statistics/Wind_in_power_annual_statistics_2012.pdf.

[9] J. Horta, D. Kofman, D. Menga, Novel Paradigms for Advanced Distribution Grid Energy Management, Retrieved from Telecom ParisTech, 2016, http://www.theblockchain.com/docs/ Novelparadigmsforadvanceddistributiongridenergymanagement.pdf.

[10] C.S. Karavas, G. Kyriakarakos, K.G. Arvanitis, G. Papadakis, A multi-agent decen tralized energy management system based on distributed intelligence for the design and control of autonomous polygeneration microgrids, Energy Convers. Manage. 103 (2015) 166-179, https://doi.org/10.1016/j.enconman.2015.06.021.

[11] E. Mengelkamp, B. Notheisen, C. Beer, D. Dauer, C. Weinhardt, A blockchain-based smart grid: towards sustainable local energy markets, Comput. Sci. - Res. Dev. 33 (1-2) (2017) 207-214, https://doi.org/10.1007/s00450-017-0360-9.

[12] EC, Clean Energy for All Europeans Communication, Retrieved from Eur-lex, Brussels, 2016https://ec.europa.eu/transparency/regdoc/rep/1/2016/EN/COM2016-860-F1-EN-MAIN.PDF.

[13] REScoop, What Local Energy Communities Need from the Clean Energy Package, Retrieved from (2017), pp. 1-9 https://www.duurzameenergie.org/f/files/ download/rescoop-position-paper-on-clean-energy-package-final.pdf.

[14] K. Boroojeni, M.H. Amini, A. Nejadpak, T. Dragicevic, S.S. Iyengar, F. Blaabjerg, A novel cloud-based platform for implementation of oblivious power routing for clusters of microgrids, IEEE Access 5 (2017) 607-619, https://doi.org/10.1109/ ACCESS.2016.2646418.

[15] S.C. Mueller, H. Georg, J. Nutaro, E. Widl, Y. Deng, P. Palensky, et al., Interfacing power system and ICT simulators: challenges, state-of-the-art, and case studies, IEEE Trans. Smart Grid 9 (1) (2016), https://doi.org/10.1109/TSG.2016. 2542824 1-1.

[16] E.M. Gui, I. MacGill, Typology of future clean energy communities: an exploratory structure, opportunities, and challenges, Energy Res. Soc. Sci. 35 (October) (2018) 94-107, https://doi.org/10.1016/j.erss.2017.10.019.

[17] M. Swan, Blueprint for a New Economy, (2015), https://doi.org/10.1017/ CBO9781107415324.004 O'Reilly Media, Inc..

[18] Z. Zheng, S. Xie, H. Dai, X. Chen, H. Wang, An overview of blockchain technology: architecture, consensus, and future trends, Proceedings - 2017 IEEE 6th International Congress on Big Data (2017) 557-564, https://doi.org/10.1109/ BigDataCongress.2017.85.

[19] P. Pinson, T. Baroche, F. Moret, T. Sousa, E. Sorin, S. You, The Emergence of Consumer-Centric Electricity Markets, Retrieved from (2017) http://pierrepinson. com/docs/pinsonetal17consumercentric.pdf.

[20] World Energy Council, The Developing Role of Blockchain, Retrieved from (2017) https://www.worldenergy.org/wp-content/uploads/2017/11/Blockchain_fullpaper_FINAL.pdf.

[21] J. Mattila, T.S.C.N.R. Stahl, M.T.A.B.J. Seppälä, Industrial blockchain platforms: an exercise in use case development in the energy industry, Int. J. Acad. Bus. World 2420 (3) (2016) 0-25 doi: 10.1017/CBO9781107415324.004.

[22] Bloomberg, Market for Digitalization in Energy Sector to Grow to $\$ 64 \mathrm{BN}$ by 2025 | Bloomberg New Energy Finance, Retrieved April 23, 2018, from (2017) https:/ about.bnef.com/blog/market-digitalization-energy-sector-grow-64bn-2025/.

[23] ICTU, Whitepaper Blockchain, Retrieved from (2016) https://www.da2020.nl/ sites/default/files/2017-03/Verkenningen_WhitepaperICTU_Blockchain_0.pdf.
[24] McKinsey, How Blockchains Could Change the World, Retrieved May 16, 2018, from (2016) https://www.mckinsey.com/industries/high-tech/our-insights/how blockchains-could-change-the-world.

[25] M. Merz, Potential of the blockchain technology in energy trading, Blockchain Technology Introduction for Business and IT Managers (2016) 51-98, https://doi org $/ 10.1515 / 9783110488951$.

[26] C. Burger, A. Kuhlmann, P. Richard, J. Weinmann, Blockchain in the Energy Transition. A Survey among Decision-Makers in the German Energy Industry, Retrieved from German Energy Agency, 2016, p. 41 https://www.dena.de/ fileadmin/dena/Dokumente/Meldungen/dena_ESMT_Studie_blockchain_englisch. pdf.

[27] F. Holotiuk, F. Pisani, J. Moormann, The impact of blockchain technology on business models in the payments industry, WI 2017 Proceedings, (2017), pp. 912-926 Retrieved from https://wi2017.ch/images/wi2017-0263.pdf.

[28] C. Martin, How Blockchain is Threatening to Kill the Traditional Utility, Retrieved from Bloomberg, 2018, https://www.bloomberg.com/news/articles/2018-04-09/ blockchain-latest-death-knell-of-an-old-school-utility-model.

[29] M.E. Peck, D. Wagman, Energy Trading for Fun and Profit Buy your neighbor's rooftop solar power or sell your own- it'll all be on a blockchain, IEEE Spectr. 54 (10) (2017) 56-61, https://doi.org/10.1109/MSPEC.2017.8048841.

[30] J. Farla, J. Markard, R. Raven, L. Coenen, Sustainability transitions in the making: a closer look at actors, strategies and resources, Technol. Forecast. Soc. Change 79 (6) (2012) 991-998, https://doi.org/10.1016/j.techfore.2012.02.001.

[31] S. Jacobsson, A. Johnson, The diffusion of renewable energy technology: an analytical framework and key issues for research, Energy Policy 28 (9) (2000) 625-640, https://doi.org/10.1016/S0301-4215(00)00041-0.

[32] J. Schot, F.W. Geels, Strategic niche management and sustainable innovation journeys: theory, findings, research agenda, and policy, Technol. Anal. Strateg. Manag. 20 (5) (2008) 537-554, https://doi.org/10.1080/09537320802292651.

[33] D.J. Spielman, K. Davis, M. Negash, G. Ayele, Rural innovation systems and networks: findings from a study of Ethiopian smallholders, Agric. Hum. Values 28 (2) (2011) 195-212, https://doi.org/10.1007/s10460-010-9273-y.

[34] J. Köhler, F.W. Geels, F. Kern, J. Markard, A. Wieczorek, F. Alkemade, et al., An agenda for sustainability transitions research: state of the art and future directions, Environ. Innov. Soc. Transit. (2019).

[35] B. Elzen, A. Wieczorek, Transitions towards sustainability through system innovation, Technol. Forecast. Soc. Change 72 (6) (2005) 651-661.

[36] R. Kemp, J. Schot, R. Hoogma, Regime shifts to sustainability through processes of niche formation: the approach of strategic niche management, Technol. Anal. Strateg. Manag. 10 (2) (1998) 175-198, https://doi.org/10.1080/ 09537329808524310

[37] M.C.J. Caniëls, H.A. Romijn, Actor networks in Stategic Niche Management: insights from social network theory, Futures 40 (2008) 613-629, https://doi.org/10 1016/j.futures.2007.12.005.

[38] A. Lopolito, P. Morone, R. Sisto, Innovation niches and socio-technical transition: a case study of bio-refinery production, Futures 43 (1) (2011) 27-38.

[39] F. Hermans, D. Van Apeldoorn, M. Stuiver, K. Kok, Niches and networks: explaining network evolution through niche formation processes, Research 42 (3) (2013) 613-623.

[40] S. Wasserman, J. Galaskiewicz, Advances in Social Network Analysis: Research in the Social and Behavioral Sciences, Sage Publications, 1994, https://doi.org/10. $4135 / 9781452243528$

[41] J. Esparcia, Innovation and networks in rural areas. An analysis from European innovative projects, J. Rural Stud. 34 (2014) 1-14.

[42] N.M. Tichy, M.L. Tushman, C. Fombrun, Social network analysis for organizations, Acad. Manage. Rev. Soc. Netw. Anal. Organ. 4 (4) (1979) 507-519 Source: The Academy of Management Review Academy of Management Review, Retrieved from http://www.jstor.org/stable/257851.

[43] J. Scott, Social network analysis, Sociology 22 (1) (2000) 109-127.

[44] R.L. Breiger, The analysis of social networks, Handbook of Data Analysis, (2004), pp. 505-526, https://doi.org/10.4135/9781848608184.n22.

[45] C.R. De Rolt, J. Da, S. Dias, F. Tiago, G. Peña, Network analysis as a management tool for inter-organizational projects, Gestão Produção 24 (2) (2017) 266-278, https://doi.org/10.1590/0104-530X1885-16.

[46] J. Moody, D. Mcfarland, S. Bender-deMoll, Dynamic network visualization 1, Am. J. Sociol. 110 (4) (2005) 1206-1241, https://doi.org/10.1086/421509.

[47] P. Hawe, C. Webster, A. Shiell, A glossary of terms for navigating the field of social network analysis, J. Epidemiol. Community Health 58 (12) (2004) 971-975, https://doi.org/10.1136/jech.2003.014530.

[48] S.P. Borgatti, P.C. Foster, The network paradigm in organizational research: a review and typology, J. Manage. (2003), https://doi.org/10.1016/S0149-2063(03) 00087-4.

[49] J. Coleman, Social capital in the creation of human capital, Knowledge and Social Capital Vol. 94 (2000), pp. 17-41, https://doi.org/10.1016/B978-0-7506-7222-1. 50005-2.

[50] R.S. Burt, Structural holes versus network closure as social capital, Social Capital: Theory and Research, (2001), https://doi.org/10.4324/9781315129457-2.

[51] CWI, E. Pauwel, CWI joins the Dutch National Blockchain Coalition as a founding Member, Blockchain Eng. (2017) 35 Retrieved from www.ercim.eu.

[52] Alliander, Spectral, Blockchain: Jouliette @ De Ceuvel, Retrieved December 2, 2018, from (2017) https://www.jouliette.net/blockchain.html.

[53] Stedin, Energy21, Whitepaper: Layered Energy System - Inclusive Enablement of Local Power, (2018).

[54] C. Akasiadis, G. Chalkiadakis, Decentralized Large-Scale Electricity Consumption Shifting by Prosumer Cooperatives, (2016), pp. 175-183 ECAI, Retrieved from http://ebooks.iospress.nl/publication/44756. 
[55] T. Lundqvist, A. de Blanche, H.R.H. Andersson, Thing-to-thing electricity micro payments using blockchain technology, 2017 Global Internet of Things Summit (GIoTS) (2017) 1-6, https://doi.org/10.1109/GIOTS.2017.8016254.

[56] M.A. Mustafa, S. Cleemput, A. Abidin, A local electricity trading Market: security analysis, Innovative Smart Grid Technologies Conference Europe (ISGT-Europe) 2017 (2017) 1-6 Retrieved from https://www.esat.kuleuven.be/cosic/ publications/article-2658.pdf.

[57] C. Zhang, J. Wu, C. Long, M. Cheng, Review of existing peer-to-peer energy trading projects, Energy Procedia 105 (2017) 2563-2568, https://doi.org/10.1016/j. egypro.2017.03.737.

[58] S.P. Borgatti, M.G. Everett, The centrality of groups and classes, J. Math. Sociol. 23 (3) (1999) 181-201 Retrieved from http://www.analytictech.com/borgatti/group_ centrality.htm.

[59] K. Meagher, M. Rogers, Network density and R\&D spillovers, J. Econ. Behav. Organ. 53 (2) (2004) 237-260, https://doi.org/10.1016/j.jebo.2002.10.004.

[60] IEA, Digitalization \& Energy, Retrieved from (2017), p. 188 http://www.iea.org/ publications/freepublications/publication/DigitalizationandEnergy3.pdf.

[61] R.R. Sharma, S. Mukherji, Organizational transformation for sustainable development: a case study, Management of Permanent Change, (2015), pp. 195-216, https://doi.org/10.1007/978-3-658-05014-6_11.
[62] Statkraft, Digitalization in the Energy Industry - Statkraft Summer Project Blog, Retrieved April 23, 2018, from (2017) https://statkraftsummerproject.wordpress. $\mathrm{com} / 2017 / 08 / 07 /$ digitalization-in-the-energy-industry/.

[63] S. Aiman, S. Hassan, A. Habbal, A. Rosli, A.H.M. Shabli, Smart electricity billing system using blockchain technology, J. Telecommun. Electron. Comput. Eng. 10 (2-4) (2018) 91-94 Retrieved from http://journal.utem.edu.my/index.php/jtec/ article/viewFile/4323/3170.

[64] F. Imbault, M. Swiatek, R. De Beaufort, R. Plana, The green blockchain: managing decentralized energy production and consumption, Conference Proceedings - 2017 17th IEEE International Conference on Environment and Electrical Engineering and 2017 1st IEEE Industrial and Commercial Power Systems Europe (2017), https:// doi.org/10.1109/EEEIC.2017.7977613.

[65] S. Noor, W. Yang, M. Guo, K.H. van Dam, X. Wang, Energy Demand Side Management within micro-grid networks enhanced by blockchain, Appl. Energy 228 (2018) 1385-1398, https://doi.org/10.1016/j.apenergy.2018.07.012.

[66] G. Verbong, F. Geels, The ongoing energy transition: lessons from a socio-technical, multi-level analysis of the Dutch electricity system (1960-2004), Energy Policy 35 (2) (2007) 1025-1037, https://doi.org/10.1016/j.enpol.2006.02.010.

[67] F.W. Geels, W.A. Smit, Failed technology futures: pitfalls and lessons from a historical survey, Futures 32 (9-10) (2000) 867-885. 